\title{
Frost heave modelling using porosity rate function
}

\author{
Radoslaw L. Michalowski*,†, and Ming Zhu ${ }^{\S}$ \\ Department of Civil and Environmental Engineering, University of Michigan, Ann Arbor, MI 48109-2125, U.S.A.
}

\begin{abstract}
SUMMARY
Frost-susceptible soils are characterized by their sensitivity to freezing that is manifested in heaving of the ground surface. While significant contributions to explaining the nature of frost heave in soils were published in late 1920s, modelling efforts did not start until decades later. Several models describing the heaving process have been developed in the past, but none of them has been generally accepted as a tool in engineering applications. The approach explored in this paper is based on the concept of the porosity rate function dependent on two primary material parameters: the maximum rate, and the temperature at which the maximum rate occurs. The porosity rate is indicative of ice growth, and this growth is also dependent on the temperature gradient and the stress state in the freezing soil. The advantage of this approach over earlier models stems from a formulation consistent with continuum mechanics that makes it possible to generalize the model to arbitrary three-dimensional processes, and use the standard numerical techniques in solving boundary value problems. The physical premise for the model is discussed first, and the development of the constitutive model is outlined. The model is implemented in a 2-D finite element code, and the porosity rate function is calibrated and validated. Effectiveness of the model is then illustrated in an example of freezing of a vertical cut in frost-susceptible soil. Copyright (C) 2006 John Wiley \& Sons, Ltd.
\end{abstract}

KEY WORDS: frost heave; ice growth; porosity rate; frost susceptibility; soil freezing; phase change; constitutive model

\section{INTRODUCTION}

Frost heaving and thawing is a major cause of damage to transportation infrastructure in regions of seasonal frost. It is also a cause of damage to structures with footings placed in frost susceptible soils above freezing depth, and a source of interruptions in pipeline operations. When granular soils, such as sand, are subjected to freezing, the moisture in the soil undergoes phase change, forming what is usually referred to as the pore ice. This freezing process is often called freezing in situ. The moisture in silts and clays subjected to quick freezing (i.e. freezing

\footnotetext{
*Correspondence to: Radoslaw L. Michalowski, Department of Civil and Environmental Engineering, University of Michigan, 2340 G.G. Brown Bldg., Ann Arbor, MI 48109-2125, U.S.A.

†E-mail: rlmich@umich.edu

Professor.

${ }^{\S}$ Graduate Research Assistant.
}

Contract/grant sponsor: U.S. Army Research Office; contract/grant number: DAAD19-03-1-0063

Received 18 May 2005

Copyright (C) 2006 John Wiley \& Sons, Ltd.

Revised 24 November 2005

Accepted 28 November 2005 


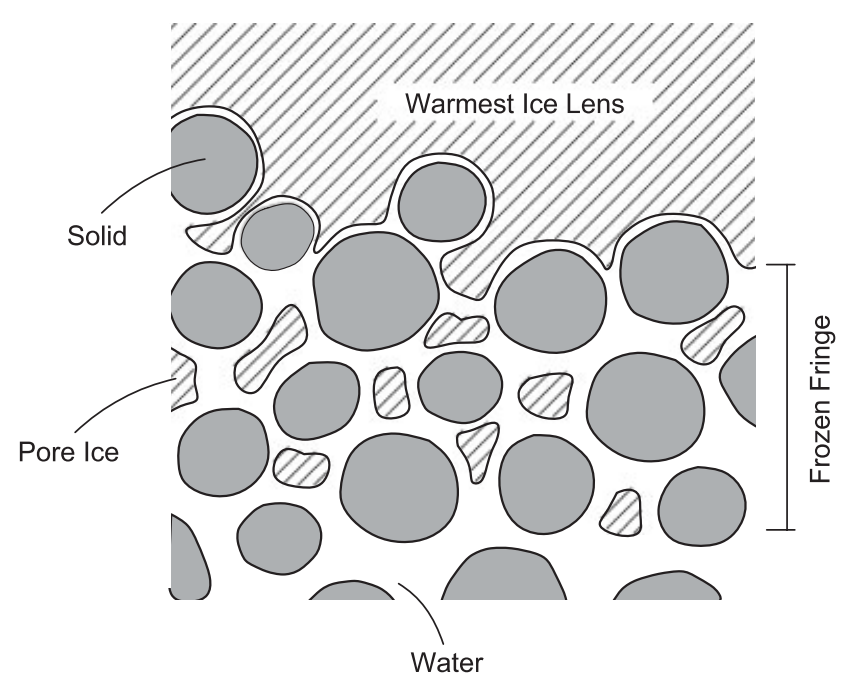

Figure 1. Freezing zone in frost-susceptible soil.

with a fast-moving freezing front) will also freeze in situ, but a slow-moving freezing front may cause unfrozen moisture movement toward the freezing front, and induce accumulation of ice in the form of ice lenses. The soils that promote formation of ice lenses during freezing processes, leading to frost heaving, are called frost-susceptible soils.

The freezing front in the soil relates to the isotherm at the freezing point of water, typically $0^{\circ} \mathrm{C}(273.15 \mathrm{~K})$, but it can vary, for instance, due to the presence of solutes. A band of soil in the proximity of the freezing front on its cold side is called the frozen fringe. The pores of the soil in the frozen fringe are filled with water and ice, Figure 1. When the freezing front, with its trailing frozen fringe, propagates through the frost susceptible soil, ice lenses form periodically behind the frozen fringe. Accumulation of the ice lenses then gives rise to the frost heave observed at the surface of the soil.

Frost-susceptible soils have a granulometric composition typical of silt, but soils with a larger amount of fine particles, such as clays, are also known to heave. Consequently, these soils are of particular concern in cold regions. Frost heave is caused by moisture transfer from the unfrozen soil into the freezing zone, and the formation of ice lenses. Upon thawing, the ice lenses become a source of excess water that contributes to significant weakening of the soil. An effort is described in this paper toward constructing a constitutive model of soil that will allow assessing the accumulation of ice in the freezing phase of the freeze-thaw cycle.

There are three necessary conditions for frost heave to occur: (a) frost susceptible soil, (b) availability of water, and (c) freezing temperatures, or, more specifically, thermal conditions that will cause freezing front propagation slow enough to allow water transport. As indicated earlier, if the propagation of the freezing front occurs at a high rate, water freezes in situ, and no ice lenses are formed even in frost-susceptible soils. Understanding the phenomenon and the development of predictive tools will allow anticipating the adverse consequences of frost heaving on structures and preventing these consequences at the design stage.

Systematic studies of soil freezing were performed early by Taber [1,2] who showed that some soils will heave when subjected to freezing in an 'open system' (a system allowing for moisture 
transfer from an outside source into the specimen). It was a common perception at the time that the expansion of water upon freezing plays a significant role in this process, but Taber's experiments clearly indicated that it is not so. A series of experiments with freezing specimens where water was replaced with benzene or nitrobenzene exhibited the phenomenon of frost heave, even though both benzene and nitrobenzene contract upon freezing. Frost heave is then attributed to moisture migration into the freezing zone and ice growth (segregated ice lenses), and not to the fluid expansion upon phase change. Other early contributions to frost heave research are those of Beskow [3].

Although the systematic studies were initiated in the 1920s by Taber, efforts toward producing predictive tools did not start till decades later. The capillary theory of frost heaving was developed in the 1960s $[4,5]$. Based on the Laplace surface tension formula, the simplicity of the capillary theory was attractive, but the true pressures developed during the frost heave process were found to be far greater than those predicted by the theory. In addition, there was evidence that ice lenses can grow within frozen soil at some distance behind the freezing front, which could not be explained by the capillary theory.

A model that caught the attention of both physicists and engineers was developed in the 1980 s, and it is referred to as the rigid ice model. The early proposal of this model was presented by Miller [6], and further developments were described in O'Neill and Miller [7, 8]. This model takes notice of a phenomenon called regelation (or refreezing). If a wire is draped over a block of ice, with both ends of the wire loaded with weights, the wire will gradually cut into the block and move through the block. The ice in direct contact beneath the wire gradually melts as the melting point of water is depressed by the contact stress, and the melted water travels around the wire and refreezes above it, allowing the wire to travel through the ice. The mechanism of regelation was central to Miller's concept of the secondary frost heaving that gave rise to the rigid ice model. If a small mineral particle is embedded in a block of ice subjected to a temperature gradient, the particle will travel toward the warmer side of the block (up the temperature gradient). This is caused by the very same mechanism of regelation, where the ice melts at the warm side of the particle, melted water travels around the particle, and refreezes at the cold side, Figure 2(a). The key experiment for the particle migration was presented by Römkens and Miller [9]. A frost-susceptible soil subjected to freezing is now viewed as an assembly of particles, with the pore water frozen in situ, but connected, forming one ice body. Hence, the particles are embedded in what can be considered a block of ice, Figure 2(b), and they attempt to move up the temperature gradient (downward). However, they are kinematically constrained by other particles beneath; therefore, it is the ice that moves upward, the relative motion being consistent with the particle migration in Figure 2(a). Now, a new ice lens is initiated when the pore pressure (combined suction in unfrozen water and pressure in the ice frozen in situ) becomes equal to the overburden. The model of frost heave based on the description above is called the rigid ice model. While this is a reasonable, physically-based explanation of the frost heave process, efforts toward producing a computational model ended with a one-dimensional numerical scheme, the most recent one described in Reference [10].

In addition to the rigid ice model, at least three other groups of models can be distinguished: (a) semi-empirical, (b) hydrodynamic, and (c) thermomechanic models. The segregation potential model rose from an empirical effort to explain the behaviour of a specimen subjected to freezing. Subsequently, the concept of segregation potential $\left(\mathrm{SP}_{0}\right)$ was introduced, Konrad and Morgenstern [11], which relates the water flux $\left(v_{0}\right)$ to the temperature gradient in the frozen fringe, $v_{0}=\mathrm{SP}_{0}$ grad $T$. Hydrodynamic models utilize the mass and energy balance with the 

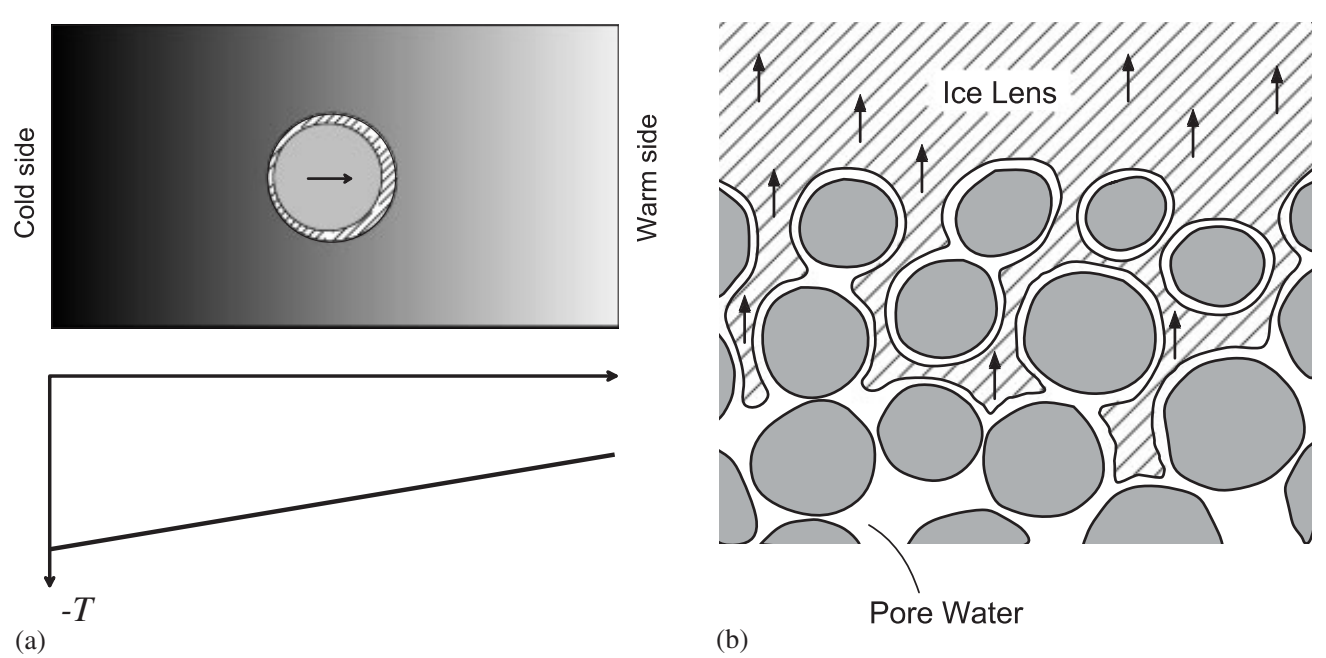

Figure 2. Regelation process: (a) particle migration in a block of ice; and (b) rigid ice concept.

cryogenic suction determined from the Clausius-Clapeyron equation. The heave then occurs when the ice content exceeds some critical value. For instance, Kay et al. [12] used a criterion of soil porosity minus the unfrozen water content, while Taylor and Luthin [13] and Shen and Ladanyi [14] used an ice content equal to $85 \%$ of porosity as the heave criterion.

The model described in this paper belongs to the last group: thermomechanic models. These models do not predict formation of individual ice lenses; rather the ice growth is distributed over the finite volume of the soil, and a global response of the freezing soil is sought [15-18]. This paper is an extension of an earlier effort [17], where the porosity rate was introduced as a constitutive function. This function has been modified in this paper to better reproduce the experimental measurements, it has been calibrated for a soil for which comprehensive data was found in the literature, and the entire model has now been implemented in a finite element code.

The fundamental constitutive function used in the model, the porosity rate, will be discussed in Sections 2 and 3, first as a scalar function and then as a growth tensor. Other properties of the soil model: unfrozen water content in frozen soil, heat capacity, and soil deformability will be described in Sections 4-6. Calibration of the model and its validation using experimental test results are then described in Sections 7 and 8, respectively. Implementation of the model will be illustrated in the penultimate section, and final remarks will conclude the paper.

\section{POROSITY RATE FUNCTION}

Frost susceptibility is a material property, and the soil tendency to form ice lenses during freezing needs to be embedded in a constitutive function that will account for the physical process observed in freezing soils. In an earlier attempt at constructing a constitutive model for frost susceptible soils, a porosity rate function was introduced as a material function that determines the ability of the soil to increase in volume due to growth of ice. However, this function does not model the growth of an individual ice lens; rather, it describes an increase in 
soil porosity that is caused by an influx of water into the freezing zone, which leads to the growth of ice behind the freezing front.

Such phenomenological (or macroscopic) modelling of ice growth and frost heaving can be successful only if the porosity rate function is selected such that the physical processes at the microscopic level are reflected in this function. The term microscopic here pertains to the processes between the components of the freezing soil, whereas the macroscopic is the global effect at the level of the mixture.

Experimental evidence shows that the intense growth of ice lenses occurs at a temperature slightly below the freezing point of water (e.g. Reference [19]), and it tapers off with a further decrease in temperature. Silts have a tendency to grow ice at a high rate, but this growth is quickly inhibited with a drop in the temperature. Frost susceptible clays, on the other hand, heave at a lower rate, but the growth of ice still occurs at lower temperatures. These effects must be captured with a phenomenological function describing the rate of porosity 'growth' in the freezing soil. Such a function was considered earlier [15,17]; here we introduce a modified porosity rate function that was found to conform better to the experimental results (calibration of this function will be shown later in this paper). The core of this function is given in the following form:

$$
\dot{n}=\dot{n}_{\mathrm{m}}\left(\frac{T-T_{0}}{T_{\mathrm{m}}}\right)^{2} \mathrm{e}^{1-\left(T-T_{0} / T_{\mathrm{m}}\right)^{2}}, \quad T<T_{0}, \quad \frac{\partial T}{\partial t}<0
$$

where $\dot{n}_{\mathrm{m}}$ is the maximum porosity rate for a given soil, and $T_{\mathrm{m}}$ is the temperature $\left({ }^{\circ} \mathrm{C}\right)$ at which this maximum occurs, see Figure 3. The freezing point of water is denoted by $T_{0}$, and $T$ (both in ${ }^{\circ} \mathrm{C}$ ) is the average temperature in the constituents of the mixture in an element where the increase of porosity is calculated. The two material properties in Equation (1) are: $\dot{n}_{\mathrm{m}}\left(\mathrm{s}^{-1}\right)$ and $T_{\mathrm{m}}\left({ }^{\circ} \mathrm{C}\right)$. This function is valid for the freezing branch of the freeze-thaw cycle $\left(T<T_{0}\right.$, $\partial T / \partial t<0)$.

The porosity rate expressed in Equation (1) captures the experimentally observed increase in ice content in frost susceptible soils well as a function of temperature. However, the growth of ice is affected considerably by at least two other variables: the temperature gradient, and the

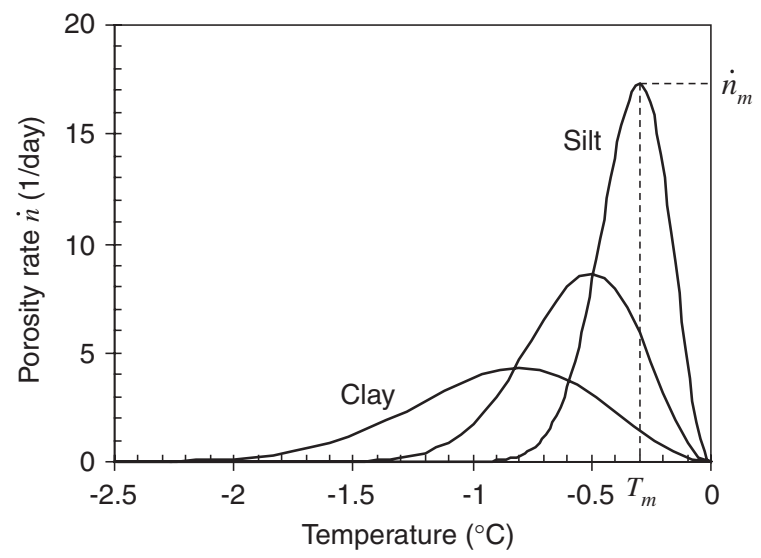

Figure 3. Porosity rate function. 
stress state. To account for those, the function is modified as follows:

$$
\dot{n}=\dot{n}_{\mathrm{m}}\left(\frac{T-T_{0}}{T_{\mathrm{m}}}\right)^{2} \cdot \mathrm{e}^{1-\left(T-T_{0} / T_{\mathrm{m}}\right)^{2}} \cdot \frac{\left|\frac{\partial T}{\partial l}\right|}{g_{\mathrm{T}}} \cdot \mathrm{e}^{-\left|\sigma_{k k}\right| / \varsigma}
$$

where the last factor (dependent on stress) has a character analogous to a retardation coefficient. The maximum porosity rate $\dot{n}_{\mathrm{m}}$ in Equation (2) reflects the maximum rate determined at one well-defined temperature gradient $g_{\mathrm{T}}$. However, quotient $\dot{n}_{\mathrm{m}} / g_{\mathrm{T}}$ (with $\dot{n}_{\mathrm{m}}$ determined at temperature gradient $g_{\mathrm{T}}$ ) is a material constant for a given soil. As $\dot{n}_{\mathrm{m}} / g_{\mathrm{T}}$ is constant, a test with any distribution of the temperature gradient can be used to determine the value of $\dot{n}_{\mathrm{m}} / g_{\mathrm{T}}$.

The gradient of temperature in Equation (2) is taken in direction $l$ that coincides with the $l$-direction in Figure 4. This is the direction of heat flow, or maximum temperature gradient direction. Using existing laboratory tests, it was determined that the rate of porosity growth $\dot{n}$ is proportional to $\partial T / \partial l$, and this will be later confirmed in the calibration effort. Since gradient $\partial T / \partial l$ is negative, its modulus is taken in Equation (2). The process stops (the rate of porosity in Equation (2) becomes zero) when the temperature gradient becomes zero, i.e. when the heat flow ceases.

The dependence of the porosity rate on the gradient of temperature makes the model nonlocal. The response of the soil at a given point is dependent not only on the temperature at that point, but also on the temperature in its neighbourhood, since the temperature gradient is indicative of the temperature change in its proximity. One can argue that the gradient in temperature is indicative of the proximity of freezing front. For a given temperature, the larger the temperature gradient, the closer the source of unfrozen water, thus the larger the rate of growth.

Experimental results from freezing tests of specimens subjected to substantial load ('overburden') indicate that frost heave can be inhibited or reduced by stress [20]. This dependence of heaving on the stress state must be included in the porosity rate function. If the skeleton in the freezing soil was to be interpreted as a continuum solid, the porosity growth would induce tension in the skeleton. However, the growth of ice is localized in ice lenses. In a

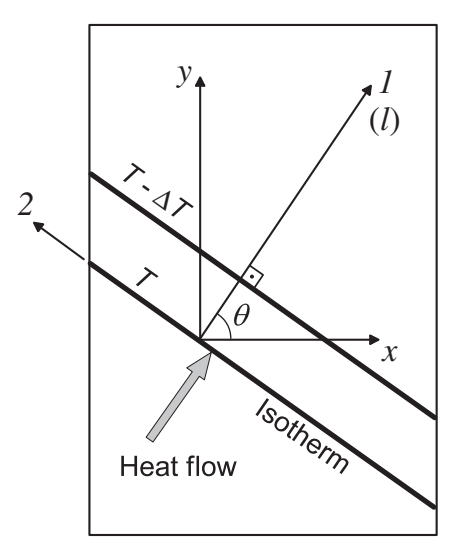

Figure 4. Co-ordinate system. 


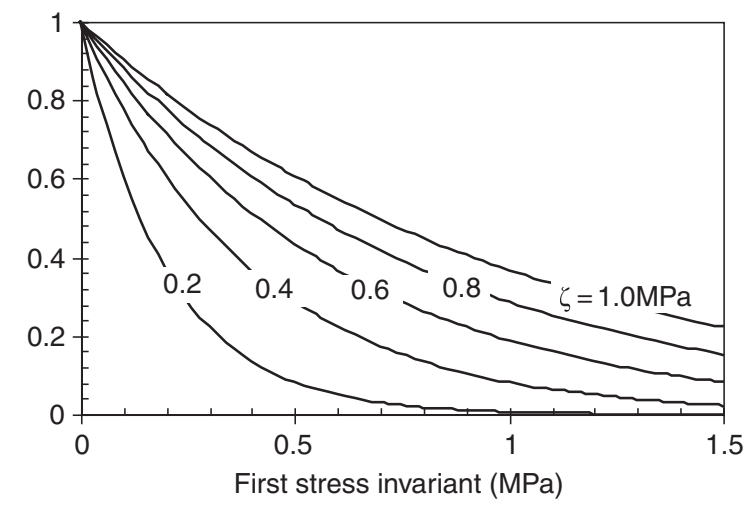

Figure 5. Influence of stress state on porosity growth.

perfect one-dimensional ice segregation process, as that described in Reference [19], the stress state in the soil skeleton remains compressive, and one could extend this observation to conclude that the tensile stresses in the skeleton induced by ice lenses growing on the cold side of the frozen fringe are negligible when compared to those induced by gravity or confinement. It was argued by Miller [6] that the onset of ice lens formation occurs when the pore pressure (stress in ice and water) increases and the effective stress in the soil drops to zero. However, reaching a zero effective stress can be inhibited by a large overburden stress. Therefore, the total stress (largely dependent on the 'overburden' and confinement of the heaving soil) has a profound influence on frost heave, and it should be used as a measure that hinders ice growth. The total stress is also a convenient measure, as it is easily calculated in the process of deformation. The last factor in Equation (2) includes a function of the first invariant of the total stress tensor in the soil, $\sigma_{k k}$. This stress function was selected in a simple form: $\exp \left(-\left|\sigma_{k k}\right| / \varsigma\right)$. This is a phenomenological function that was found to fit the experiments well for a variety of stresses, and its graphical representation is shown in Figure 5. The consequence of this assumption is that an unconfined growth of ice will produce no increase in stress. The modulus of $\sigma_{k k}$ (absolute value) is taken in Equation (2), so that the stress retardation function becomes independent of the sign convention. The function in Equation (2) is a significant revision of its earlier account [17], and, with the modifications introduced here, it was found to better model the true process of frost heaving.

Experimental test results from step-freezing processes, e.g. References [21,22], indicate that once the freezing front stabilizes at a certain level, after a period of intense growth the frost heave of the specimen reduces to a very small rate. This phenomenon is modelled introducing a porosity threshold, $n_{c}$, past which further growth ceases. Although $n_{c}$ was not reached in tests used for calibration, based on other tests, its value is expected to be in excess of 0.7 , and it was taken in step-freezing computations as 0.75 . Even if the threshold porosity is reached in some portion of the specimen, frost heave does not cease as ice continues to grow in other regions.

\section{POROSITY GROWTH TENSOR}

Ice lenses grow in the direction of heat flow on the cold side of the frozen fringe. This process, however, is not one-dimensional. Therefore, if the growth of ice lenses is to be distributed over a 
finite volume, this growth needs to be modelled as anisotropic. We use the concept of the porosity growth tensor, $\dot{n}_{i j}$, introduced earlier [17] and defined as

$$
\dot{n}_{i j}=\dot{n} \alpha_{i j}
$$

where

$$
\alpha_{i j}=\left|\begin{array}{lll}
\alpha_{11} & \alpha_{12} & \alpha_{13} \\
\alpha_{21} & \alpha_{22} & \alpha_{23} \\
\alpha_{31} & \alpha_{32} & \alpha_{33}
\end{array}\right|=\left|\begin{array}{ccc}
\xi & 0 & 0 \\
0 & (1-\xi) / 2 & 0 \\
0 & 0 & (1-\xi) / 2
\end{array}\right|
$$

is the unit growth tensor, and the dimensionless quantity $\xi$ can assume values between 0.33 and 1 . The unit growth tensor is analogous to the small strain tensor, but it represents a growth rather than deformation due to an applied load. The growth tensor in Equation (4) is specified such so that direction $l$ is the major principal growth direction, i.e. it coincides with the heat flow direction ( $l$-direction in Figure 4). In general, this tensor is not represented by a diagonal matrix. The unit growth tensor has its first invariant equal to 1 . When $\xi=0.33$, isotropic growth of porosity occurs, whereas one-dimensional growth takes place when $\xi=1$. The former is the only case when the tensor in Equation (4) is diagonal in any co-ordinate system (isotropic tensor). The values of $\xi$ between the two extreme values of 0.33 and 1 represent different patterns of anisotropic growth. Tensor $\dot{n}_{i j}$ in Equation (3) is analogous to the strain rate tensor, but it is owed to the growth of porosity rather than deformation caused by loading.

As discussed in the previous section, it is conjectured that unconfined growth will produce no increase in stress in any of the phases of the freezing soil. However, freezing and porosity growth processes under circumstances where displacements are restrained by conditions on boundaries will lead to an increase in stress, and, possibly, to restraint of the frost heaving. The increase in stress in confined soil is dependent on the macroscopic properties (stiffness) of the soil.

It needs to be emphasized that the porosity increase occurs due to the growth of ice. As the increase in ice content is governed by the porosity rate function, the influx of water necessary to feed the growing ice is also directly related to $\dot{n}$. Consequently, the porosity rate function replaces the Darcy law for water transfer in the description of heaving soil. Owing to this formulation one does not need to make assessments of the cryogenic suction and the hydraulic conductivity in the freezing soil. The former requires making arbitrary assumptions regarding the distribution of pressure in ice, so that the Clausius-Clapeyron equation can be used, whereas the hydraulic conductivity changes orders of magnitude in the freezing soil, and it is not easily determined.

\section{UNFROZEN WATER}

When the freezing front moves into an unfrozen saturated coarse granular soil, such as gravel, nearly all water freezes at $T_{0}$. However, in soils such as silt and clay, only a portion of the water (pore water) will freeze at the freezing point, and some amount of liquid water will remain at below-freezing temperatures. This unfrozen moisture content depends on the specific surface of the soil (combined particle surface in $1 \mathrm{~g}$ of the soil) and the presence of solutes, and it was described by Anderson and Tice [23] as a power function, with parameters dependent on the specific surface of the soil. The following function is chosen here to describe the presence of 


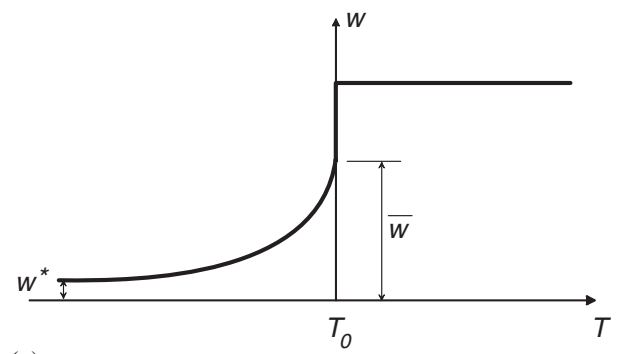

(a)

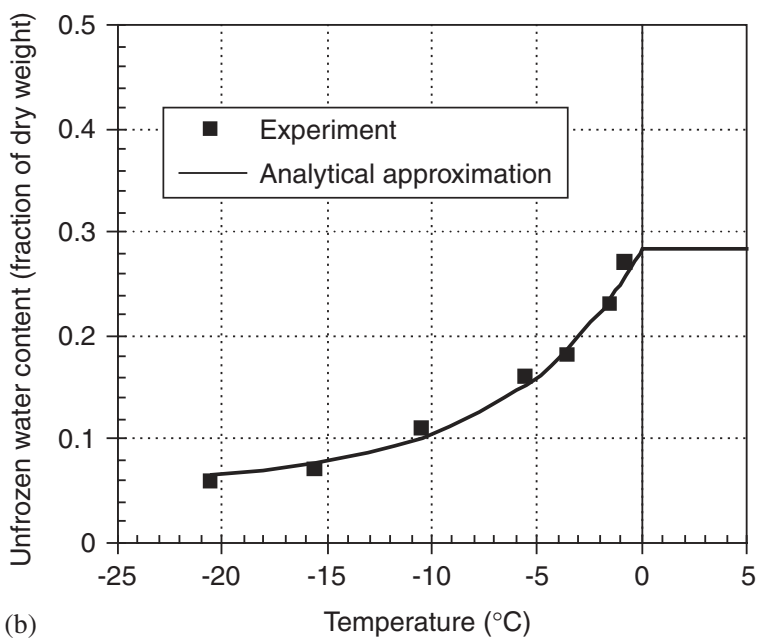

Figure 6. Unfrozen water content in frozen soil during freezing process $(\partial T / \partial t<0)$ :

(a) general form; and (b) calibration for clay.

unfrozen water in frozen soil [17], with $w$ being the unfrozen water content as a fraction of the dry weight:

$$
w=w^{*}+\left(\bar{w}-w^{*}\right) \mathrm{e}^{a\left(T-T_{0}\right)}
$$

This relation is graphically represented in Figure 6(a). A similar function, but expressed in terms of the volumetric water concentration rather than the gravimetric content, was considered earlier by Blanchard and Frémond [24]. Not all water in the soil freezes at the freezing point of water $T_{0}$; rather, there is a discontinuity at $T_{0}$, and the water content drops down to some amount $\bar{w}$, and it then decays to a small content $w^{*}$ at some reference low temperature. Parameter $a$ describes the rate of decay. The parameters in this function are specific to freezing $(\partial T / \partial t<0, T<0)$, and the thawing process does not occur along the same curve (hysteretic process). This function has an important impact on the freezing process as it indicates that some latent heat is released from the frozen soil even at temperatures well below freezing point of water.

Parameters for the function in Equation (5) used later in calculations were calibrated using the results in Fukuda et al. [22]. These results indicated that, for the clay tested, there was no discontinuity in the unfrozen water content at the freezing point, i.e. moisture content $\bar{w}$ was equal to the moisture content in the unfrozen soil, Figure 6(b). The following parameters were determined: $\bar{w}=0.285, w^{*}=0.058, a=0.16^{\circ} \mathrm{C}^{-1}$, and $T_{0}=0{ }^{\circ} \mathrm{C}$.

\section{HEAT CAPACITY AND ENERGY BALANCE}

It is convenient to introduce unfrozen water concentration $v$ as [17,24]

$$
v=\frac{V^{\mathrm{w}}}{V^{\mathrm{i}}+V^{\mathrm{w}}}
$$


where $V^{\mathrm{w}}$ and $V^{\mathrm{i}}$ are the volumes of water and ice, respectively. The volumetric fractions $\theta$ of the frozen saturated composite can then be expressed as functions of $v$ and porosity $n$

$$
\theta^{\mathrm{s}}=\frac{V^{\mathrm{s}}}{V}=1-n, \quad \theta^{\mathrm{w}}=\frac{V^{\mathrm{w}}}{V}=v n, \quad \theta^{\mathrm{i}}=\frac{V^{\mathrm{i}}}{V}=n(1-v)
$$

where superscripts s, w and i denote the soil skeleton, unfrozen water and ice, respectively. With these definitions, the mass density $\rho$ of saturated soil can be calculated as

$$
\rho=\theta^{\mathrm{s}} \rho^{\mathrm{s}}+\theta^{\mathrm{w}} \rho^{\mathrm{w}}+\theta^{\mathrm{i}} \rho^{\mathrm{i}}=(1-n) \rho^{\mathrm{s}}+v n \rho^{\mathrm{w}}+n(1-v) \rho^{\mathrm{i}}
$$

and the specific heat capacity $C$ (per unit volume) can be expressed as

$$
C=(1-n) \rho^{\mathrm{s}} c^{\mathrm{s}}+v n \rho^{\mathrm{w}} c^{\mathrm{w}}+n(1-v) \rho^{\mathrm{i}} c^{\mathrm{i}}
$$

where $c^{\mathrm{s}}, c^{\mathrm{w}}$, and $c^{\mathrm{i}}$ are the heat capacities of the constituents (per unit mass). The Fourier law of heat conduction governs the heat flow

$$
Q_{k}=-\lambda(T) \frac{\partial T}{\partial x_{k}}, \quad k=1,2,3
$$

or in vector notation

$$
\mathbf{Q}=-\lambda(T) \nabla \mathbf{T}
$$

with the heat conductivity $\lambda$ being a function of the soil composition, which, in turn, is a function of temperature $\left(\nabla \equiv\left(\partial / \partial x_{1}\right)+\left(\partial / \partial x_{2}\right)+\left(\partial / \partial x_{3}\right)\right)$. The heat conductivity of a material with several constituents can span values ranging from that for a serial connection of constituents to that for a parallel model, and it depends on the material structure. Here, we calculate the heat conductivity according to a logarithmic law

$$
\log \lambda=\theta^{\mathrm{s}} \log \lambda_{\mathrm{s}}+\theta^{\mathrm{w}} \log \lambda_{\mathrm{w}}+\theta^{\mathrm{i}} \log \lambda_{\mathrm{i}}
$$

or

$$
\lambda=\lambda_{\mathrm{s}}^{\theta^{\mathrm{s}}} \lambda_{\mathrm{w}}^{\theta^{\mathrm{w}}} \lambda_{\mathrm{i}}^{\theta^{\mathrm{i}}}
$$

Considering the heat conduction as the only form of energy exchange, the energy balance takes the form

$$
C \frac{\partial T}{\partial t}-L \frac{\partial \theta^{\mathrm{i}}}{\partial t} \rho^{\mathrm{i}}-\frac{\partial}{\partial x_{k}}\left[\lambda(T) \frac{\partial T}{\partial x_{k}}\right]=0, \quad k=1,2,3
$$

or

$$
C \frac{\partial T}{\partial t}-L \frac{\partial \theta^{\mathrm{i}}}{\partial t} \rho^{\mathrm{i}}-\nabla(\lambda \nabla T)=0
$$

where $L$ is the latent heat of fusion of water per unit mass. 


\section{DEFORMATION OF THE SOIL}

It is assumed that the response of the soil to loads is elastic (total stress analysis), but the elastic properties may depend on the temperature. The total strain increment consists of both the elastic strain increment and the strain increment induced by the porosity growth

$$
\mathrm{d} \varepsilon_{i j}=\mathrm{d} \varepsilon_{i j}^{\mathrm{e}}+\mathrm{d} \varepsilon_{i j}^{\mathrm{p}}
$$

The elastic increment in Equation (16) is defined by the elastic constitutive law

$$
\mathrm{d} \varepsilon_{i j}^{\mathrm{e}}=B_{i j k l} \mathrm{~d} \sigma_{k l}
$$

with the elastic compliance tensor $B_{i j k l}$ dependent on the temperature, and $\mathrm{d} \sigma_{k l}$ being the Cauchy total stress tensor increment.

Introducing co-ordinate system $x_{i}(i=1,2,3)$, Figure 4 , where $x_{1}$ coincides locally with the direction of the heat flow, Equation (16) can be re-written as

$$
\begin{aligned}
\mathrm{d} \varepsilon_{11} & =\frac{1}{E}\left[\mathrm{~d} \sigma_{11}-\mu\left(\mathrm{d} \sigma_{22}+\mathrm{d} \sigma_{33}\right)\right]+\xi \dot{n} \mathrm{~d} t \\
\mathrm{~d} \varepsilon_{22} & =\frac{1}{E}\left[\mathrm{~d} \sigma_{22}-\mu\left(\mathrm{d} \sigma_{11}+\mathrm{d} \sigma_{33}\right)\right]+\frac{1}{2}(1-\xi) \dot{n} \mathrm{~d} t \\
\mathrm{~d} \varepsilon_{33} & =\frac{1}{E}\left[\mathrm{~d} \sigma_{33}-\mu\left(\mathrm{d} \sigma_{11}+\mathrm{d} \sigma_{22}\right)\right]+\frac{1}{2}(1-\xi) \dot{n} \mathrm{~d} t \\
\mathrm{~d} \gamma_{12} & =\frac{\tau_{12}}{G}, \quad \mathrm{~d} \gamma_{23}=\frac{\tau_{23}}{G}, \quad \mathrm{~d} \gamma_{31}=\frac{\tau_{31}}{G}
\end{aligned}
$$

where $E$ and $\mu$ are Young's modulus and Poisson's ratio, respectively, and the shear modulus $G=E / 2(1+\mu)$. For plane strain problems $\mathrm{d} \varepsilon_{33}=\mathrm{d} \gamma_{23}=\mathrm{d} \gamma_{31}=0$, and

$$
\mathrm{d} \sigma_{33}=\mathrm{d} \sigma_{3}=\mu\left(\mathrm{d} \sigma_{11}+\mathrm{d} \sigma_{22}\right)-E \frac{1}{2}(1-\xi) \dot{n} \mathrm{~d} t
$$

Substituting Equation (19) into the first two equations of (18), the total strain increments for plane strain problems can be written conveniently as

$$
\begin{aligned}
& \mathrm{d} \varepsilon_{11}=\frac{1}{E^{\prime}}\left(\mathrm{d} \sigma_{11}-\mu^{\prime} \mathrm{d} \sigma_{22}\right)+\left[\xi+\mu \frac{1}{2}(1-\xi)\right] \dot{n} \mathrm{~d} t \\
& \mathrm{~d} \varepsilon_{22}=\frac{1}{E^{\prime}}\left(\mathrm{d} \sigma_{22}-\mu^{\prime} \mathrm{d} \sigma_{11}\right)+\frac{1}{2}(1+\mu)(1-\xi) \dot{n} \mathrm{~d} t \\
& \mathrm{~d} \gamma_{12}=\frac{\tau_{12}}{G}
\end{aligned}
$$

where $E^{\prime}=E / 1-\mu^{2}$ and $\mu^{\prime}=\mu / 1-\mu$. The first term on the right-hand side of each equation in (20) is an elastic strain increment, and the second term is due to porosity growth

$$
\left\{\begin{array}{c}
\mathrm{d} \varepsilon_{1}^{\mathrm{p}} \\
\mathrm{d} \varepsilon_{2}^{\mathrm{p}} \\
\mathrm{d} \gamma_{12}^{\mathrm{p}}
\end{array}\right\}=\left\{\begin{array}{c}
\xi+\frac{1}{2} \mu(1-\xi) \\
\frac{1}{2}(1+\mu)(1-\xi) \\
0
\end{array}\right\} \dot{n} \mathrm{~d} t
$$


Note that $\mathrm{d} \varepsilon_{1}^{\mathrm{p}}+\mathrm{d} \varepsilon_{2}^{\mathrm{p}} \neq \dot{n} \mathrm{~d} t$, because the growth of porosity in the $x_{3}$-direction is restricted under plane strain conditions in a way that $\mathrm{d} \varepsilon_{33}^{\mathrm{e}}+\mathrm{d} \varepsilon_{33}^{\mathrm{p}}=0$, and not $\mathrm{d} \varepsilon_{33}^{\mathrm{p}}=0$. As the computations will be performed in an arbitrary co-ordinate system $x-y$ (plane strain), where $x$ does not necessarily coincide with heat flow direction $l$, the strain increments due to porosity growth must be transformed to the $x, y$ co-ordinate system using the following transformation rule:

$$
\begin{aligned}
\left\{\begin{array}{l}
\mathrm{d} \varepsilon_{x}^{\mathrm{p}} \\
\mathrm{d} \varepsilon_{y}^{\mathrm{p}} \\
\mathrm{d} \gamma_{x y}^{\mathrm{p}}
\end{array}\right\} & =\left[\begin{array}{ccc}
m^{2} & n^{2} & -m n \\
n^{2} & m^{2} & m n \\
2 m n & -2 m n & m^{2}-n^{2}
\end{array}\right]\left\{\begin{array}{c}
\mathrm{d} \varepsilon_{11}^{\mathrm{p}} \\
\mathrm{d} \varepsilon_{22}^{\mathrm{p}} \\
\mathrm{d} \gamma_{12}^{\mathrm{p}}
\end{array}\right\} \\
& =\left\{\begin{array}{c}
m^{2}\left[\xi+\frac{1}{2} \mu(1-\xi)\right]+n^{2} \frac{1}{2}(1+\mu)(1-\xi) \\
n^{2}\left[\xi+\frac{1}{2} \mu(1-\xi)\right]+m^{2} \frac{1}{2}(1+\mu)(1-\xi) \\
m n(3 \xi-1)
\end{array}\right\} \dot{\mathrm{d}} \mathrm{d}
\end{aligned}
$$

where $m=\cos \theta$ and $n=\sin \theta$, and $\theta$ is the angle axis $x$ makes with heat flow direction $l$, Figure 4. The numerical computations were performed using the commercially available finite element system ABAQUS. The strain increment vector in the $x-y$ co-ordinate system was implemented in ABAQUS with the user subroutine for thermal expansion UEXPAN.

Two types of problems are considered in this paper: one-dimensional freezing (1-D heat flow) for calibration and validation of the model, and a two-dimensional implementation of the model. Plane-strain finite elements are used in all simulations.

\section{CALIBRATION OF THE MODEL}

A set of test results presented by Fukuda et al. [22] was identified for the purpose of calibrating the model. These tests were performed on cylindrical specimens of frost susceptible clay of diameter $100 \mathrm{~mm}$ and initial height of $70 \mathrm{~mm}$. The initial and boundary conditions for the tests are identified in Table I. Tests B-F and I-L identify the freezing processes with 'ramped' temperatures. These processes all start with an initial temperature of $0^{\circ} \mathrm{C}$ at the bottom plate

Table I. Boundary/initial conditions for tests of Fukuda et al. [22].

\begin{tabular}{llccc}
\hline Tests & & $\begin{array}{c}\text { Warm } \\
\text { plate (top) }\left({ }^{\circ} \mathrm{C}\right)\end{array}$ & $\begin{array}{c}\text { Cold plate } \\
\text { (bottom) }\left({ }^{\circ} \mathrm{C}\right)\end{array}$ & $\begin{array}{c}\text { Overburden } \\
\text { stress }(\mathrm{kPa})\end{array}$ \\
\hline Step freezing (testing time: $115 \mathrm{~h})$ & A & +5 & -5 & 25 \\
Ramped freezing (testing time: $47 \mathrm{~h})$ & $\mathrm{B}$ & $7-0.042 t^{*}$ & $-0.042 t$ & 25 \\
& $\mathrm{C}$ & $5-0.042 t$ & $-0.042 t$ & 25 \\
& $\mathrm{D}$ & $4-0.042 t$ & $-0.042 t$ & 25 \\
& $\mathrm{E}$, & $3-0.042 t$ & $-0.042 t$ & 25, \\
& $\mathrm{I}, \mathrm{J}$, & & & 150,300, \\
& $\mathrm{~K}, \mathrm{~L}$ & & $-0.042 t$ & 400,600 \\
& $\mathrm{~F}$ & $2-0.042 t$ & & 25 \\
\hline
\end{tabular}

${ }^{*} t=$ time $(\mathrm{h})$. 


\section{FROST HEAVE MODELLING}

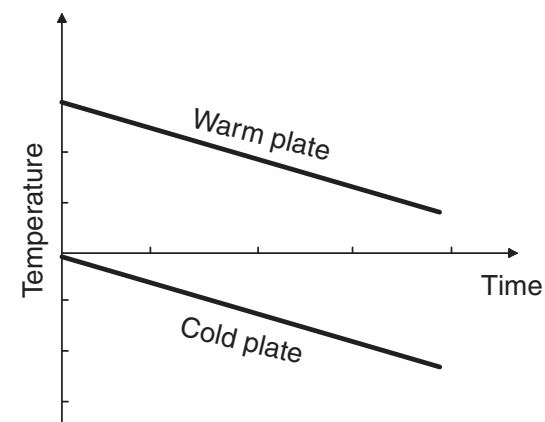

(a)

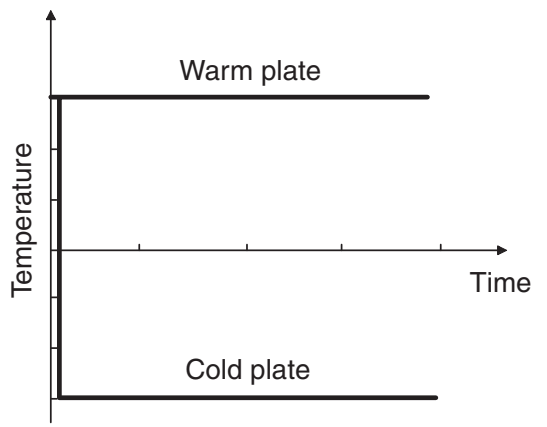

(b)

Figure 7. Specimen freezing: (a) process with ramped temperatures; and (b) step-freezing process.

and the temperature at the top plate is given in the 'warm plate' column. At time $t=0$, the temperature distribution throughout the specimen has reached steady state. The ramping process is one where the temperatures at the top and bottom plates are gradually reduced at the same rate, Figure 7(a), preserving an approximately constant temperature gradient and inducing an approximately steady penetration rate of the freezing front.

The initial temperature gradient in tests B-F is different for all specimens, and they were all tested with an overburden stress of $25 \mathrm{kPa}$. Four additional specimens, I-L, were subjected to an overburden ranging from 150 to $600 \mathrm{kPa}$. The variety of conditions in terms of the temperature gradient and the stress make the test results of Fukuda et al. [22] an ideal set to be used in the model calibration and validation effort. The test results were given in terms of the increasing heave and the freezing front penetration.

The parameters to be determined from the calibration process are those in the porosity rate function in Equation (2): $\dot{n}_{\mathrm{m}}, T_{\mathrm{m}}$, and $\zeta$. The elasticity parameters were taken as follows: Young's modulus equal to $11.2 \mathrm{MPa}$ for unfrozen soil, temperature-dependent $E=13.75|T|^{1.18}$ $\mathrm{MPa}\left(T\right.$ in $\left.{ }^{\circ} \mathrm{C}\right)$ for frozen soil below $-1{ }^{\circ} \mathrm{C}$ [25], and linear interpolation in the range 0 to $-1{ }^{\circ} \mathrm{C}$; Poisson's ratio was taken as $\mu=0.3$ for both the frozen and unfrozen soil. The remaining thermal parameters were: thermal conductivities: $1.95,0.56$, and $2.24 \mathrm{~W} \mathrm{~m}^{-1} \mathrm{~K}^{-1}$ for solid skeleton, water, and ice, respectively; heat capacities: 900,4180 , and $2100 \mathrm{~J} \mathrm{~kg}^{-1} \mathrm{~K}^{-1}$ for solid skeleton, water, and ice, respectively; latent heat of fusion of water: $3.33 \times 10^{5} \mathrm{~J} \mathrm{~kg}^{-1} \mathrm{~K}^{-1}$. These were extracted from the subject literature $[26,27]$. Other parameters were: initial porosity 0.43 , full saturation, and specific gravity of 2.62 (after Reference [22]). Parameter $\xi$ that governs the anisotropy of the ice growth in Equation (4) is difficult to assess, since no laboratory measurements are available for its evaluation. It is known, however, that the ice lenses grow predominantly in the direction of heat flow, and the value $\xi=0.9$ was adopted.

Parameters $\dot{n}_{\mathrm{m}}$ and $T_{\mathrm{m}}$ in function (2) were determined using test E, Table I. The process of model calibration is a curve 'fitting' procedure where the model-simulated process is matched with the set of calibration data. During that process the model parameters are varied so that the simulated results fit the experimental ones. It was found from the calibration process that temperature $T_{\mathrm{m}}$ greatly affects the curvature of the heave vs time curve. As expected, $\dot{n}_{\mathrm{m}}$ is the chief factor affecting the magnitude of the frost heave. A perfect match is not indicative of the accuracy of the model; it only indicates that the model is capable of predicting the characteristic features of the specimen response to given initial/boundary conditions. Validation of the model 


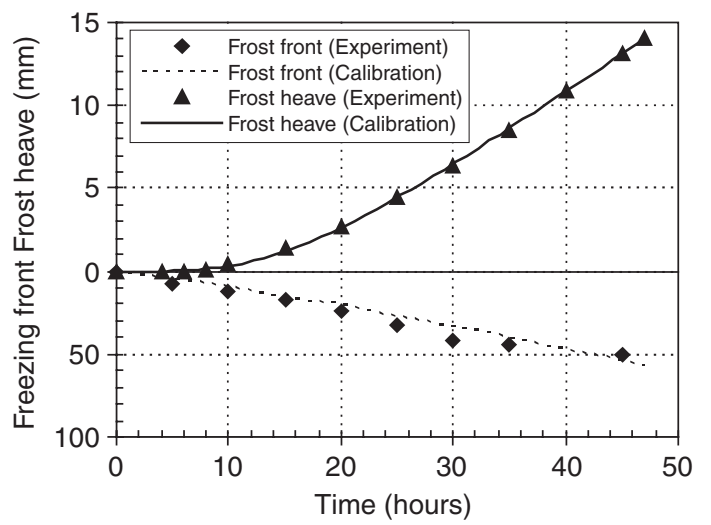

Figure 8. Calibration using test E: frost heave and freezing front propagation.

must be performed using an independent set(s) of experimental data that was not used in the calibration procedure. Here, the freezing processes with ramped temperatures, Figure 7(a), are used to calibrate the model, and frost heave data for a step-freezing process, Figure 7(b), is used for validation. The one-dimensional process is simulated using the finite element method (ABAQUS). A column of thirty plane-strain elements is used. The vertical boundaries are adiabatic and smooth, and no displacement is allowed in the horizontal direction (onedimensional deformation and heat transfer). The temperature, as a function of time, is specified on both the top and bottom boundaries of the specimen (Dirichlet boundary conditions).

The results of the calibration process using the freezing data from test $\mathrm{E}$ are illustrated in Figure 8 . The soil in this test was subjected to an overburden stress of $25 \mathrm{kPa}$, and an initial temperature gradient of $0.43^{\circ} \mathrm{C} \mathrm{cm}^{-1}$ (the temperature gradient was decreasing gradually during the test due to heave of the specimen; this change, however, was neglected). The process of heaving starts at a nearly zero rate, and, after about $25 \mathrm{~h}$, the rate of heave becomes nearly constant. The simulated frost heave curve matches the experimental results very closely, indicating that the model can well reproduce the frost heaving process associated with the ramped freezing. Propagation of the freezing front in the test is predicted with reasonable accuracy.

An additional four experimental tests performed under overburden stress in the range of $150-600 \mathrm{kPa}$ (tests I-L, Table I) were repeatedly simulated in order to calibrate parameter $\zeta$ that describes the effect of the stress. The simulated data, Figure 9, appears to fit the experimental measurements well. As a result of the calibration process the following values for the constitutive parameters were identified: $\dot{n}_{\mathrm{m}}=6.02 \times 10^{-5} \mathrm{~s}^{-1}$ (or $5.2 \times 1 / 24 \mathrm{~h}$ ) at $g_{\mathrm{T}}=100^{\circ}$ $\mathrm{C} \mathrm{m}^{-1}$, or $\dot{n}_{\mathrm{m}} / g_{\mathrm{T}}=6.02 \times 10^{-7} \mathrm{~m}^{\circ} \mathrm{C}^{-1} \mathrm{~s}^{-1}, T_{\mathrm{m}}=-0.87^{\circ} \mathrm{C}$, and $\zeta=0.6 \mathrm{MPa}$. These are parameters determined here for the clay used in the tests by Fukuda et al. [22].

\section{STEP-FREEZING AND RAMPED FREEZING (VALIDATION)}

Validation of the model is performed through comparison of the simulation results of stepfreezing and ramped freezing processes with the experimental heave measurements for these 

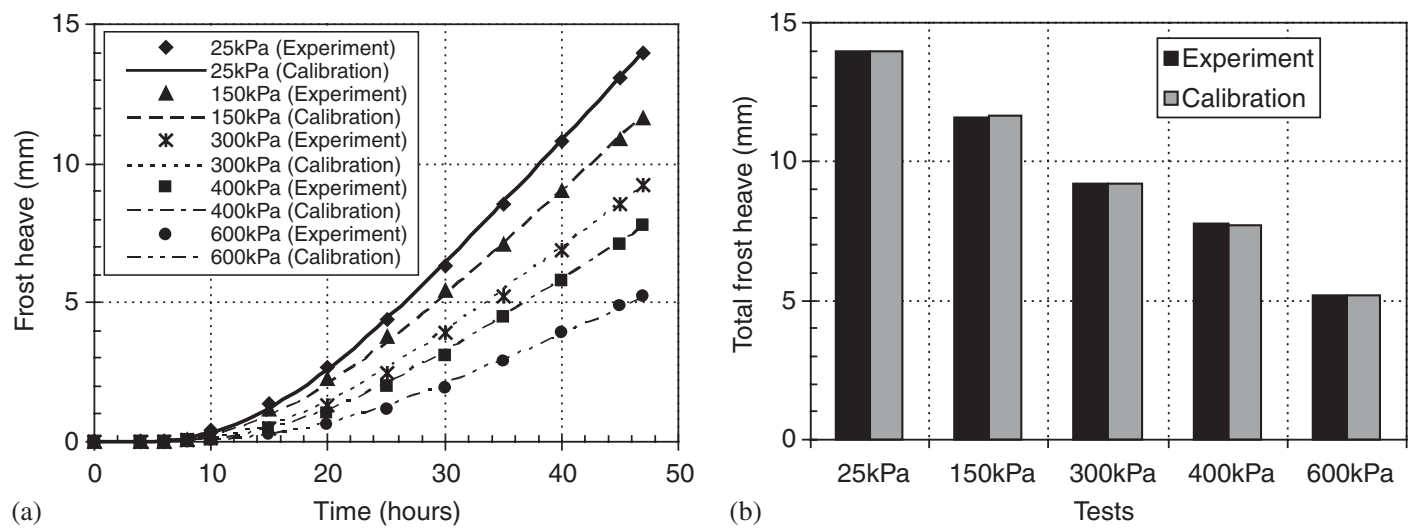

Figure 9. Calibration of the model for different overburden stresses:

(a) frost heave curves; and (b) total frost heave.
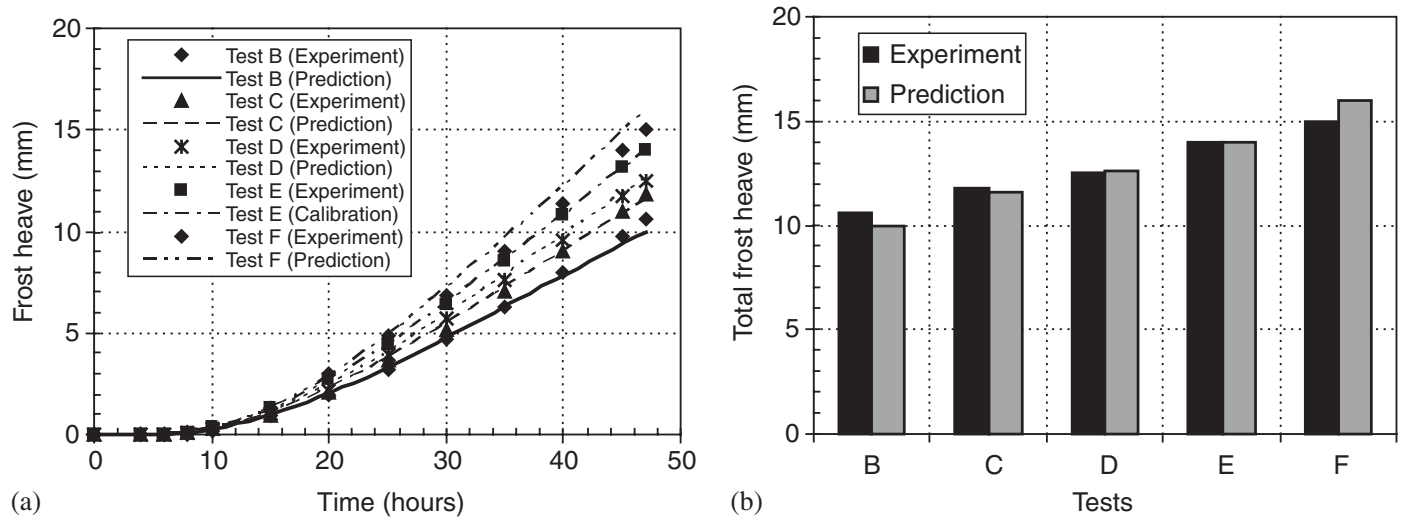

Figure 10. Validation of frost heave linear dependence on the temperature gradient: (a) comparison of the simulated and measured frost heave; and (b) total frost heave (E - calibration test).

processes. The material properties used for these simulations are those from calibration based on test results other than those used in validation (previous section).

It was assumed in Equation (2) that the dependence of the porosity growth rate on the temperature gradient is linear. This assumption is now validated through simulation of tests $\mathrm{B}$, $\mathrm{C}, \mathrm{D}$, and $\mathrm{F}$, with initial temperature gradients ranging from about 0.3 to $1.0^{\circ} \mathrm{C} \mathrm{cm}^{-1}$ (Table I). The temperature affects the phase composition of the soil, therefore the thermal conductivity, Equation (13), also depends on the temperature. Consequently, one would expect the thermal gradient to vary throughout the frozen soil even during a steady-state heat flow process. These changes have been accounted for in the computations. Simulations and the experimental measurements are illustrated in Figure 10(a). The accuracy of the fit is sufficient enough not to introduce another parameter in the model; the total heaves, simulated and measured, are shown in Figure 10(b). 

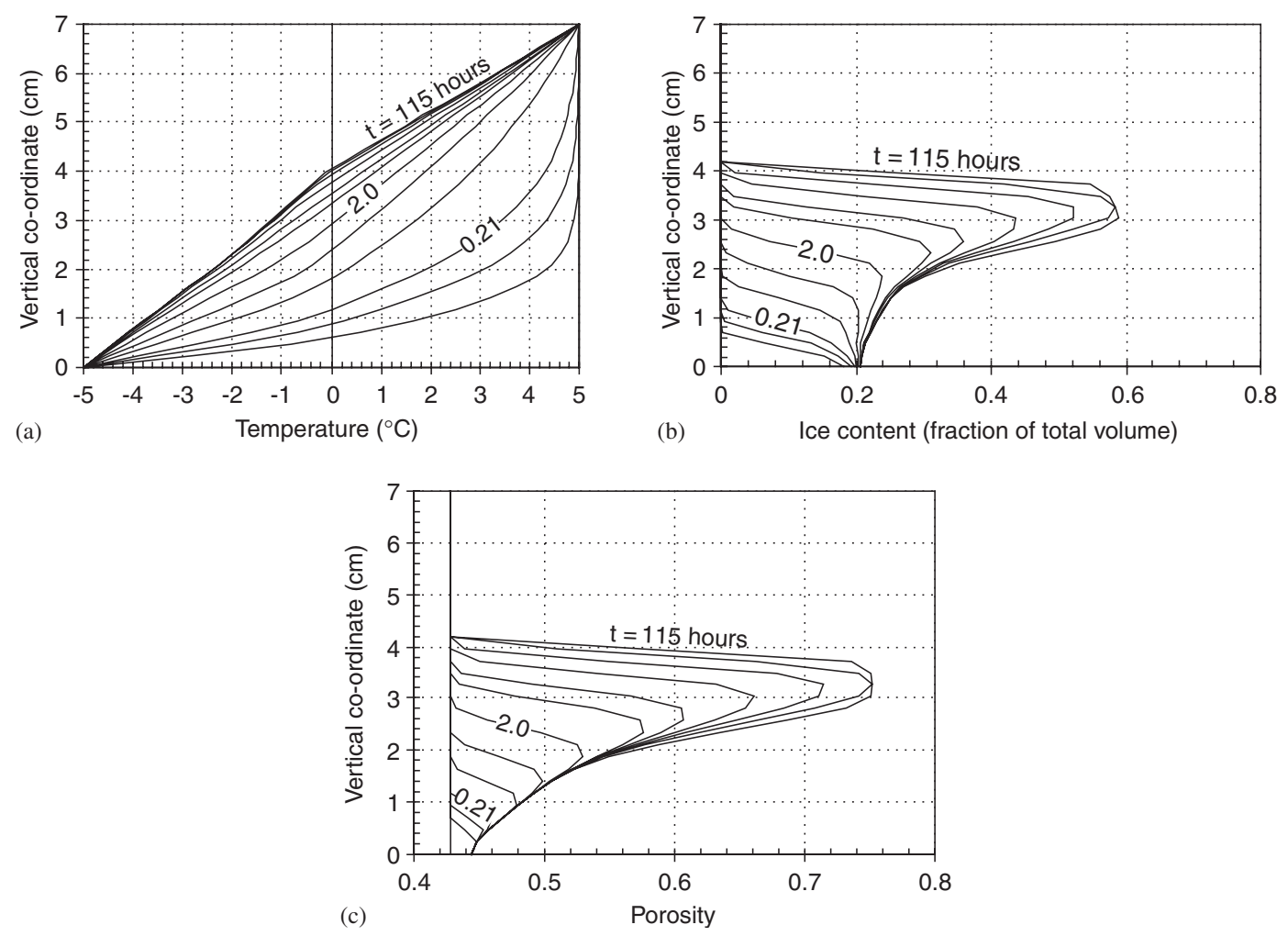

Figure 11. Step-freezing process: (a) distribution of temperature; (b) ice content; and (c) porosity.

It might be confusing at first to see that the specimen with the least temperature gradient heaved most, whereas the constitutive function (2) indicates that the larger the gradient, the larger the porosity growth. Unlike in 'element' testing, frost heave testing requires the specimen to be in a non-uniform state. The effect measured (total heave) is an integral effect over the entire specimen volume. If the temperature gradient is large, then the region within the specimen where the intense growth of ice occurs is relatively narrow, yielding a small amount of frost heave (displacement). When the gradient is small, the region undergoing ice growth is large, and the integral frost heave is large, even though, locally, the growth rate may not be as intense as in the case of a larger temperature gradient.

Further validation of the model was carried out using step-freezing process measurements (test A, Table I). The thermal initial/boundary conditions in the step-freezing process used in validation of the model were as follows: uniform initial temperature of $5^{\circ} \mathrm{C}$, at $t=0$ temperature of the bottom plate is reduced to $-5^{\circ} \mathrm{C}$, top plate remaining at $5^{\circ} \mathrm{C}$, and the process of freezing is continued for $115 \mathrm{~h}$. The freezing front propagates quickly into the specimen in the first two hours, Figure 11(a), causing in situ freezing with a small increase in porosity in the bottom section of the specimen. However, once the freezing front reaches the height of about $4 \mathrm{~cm}$, its propagation becomes very slow, and the ice content increases significantly beyond 
FROST HEAVE MODELLING

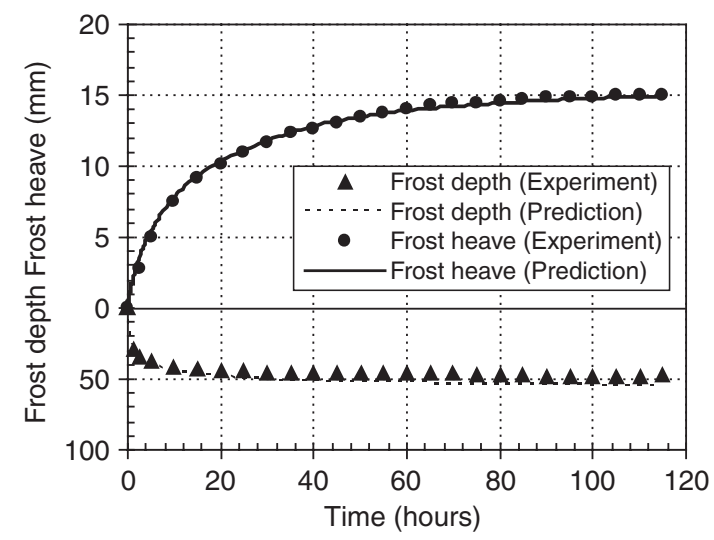

Figure 12. Step freezing: comparison of experimental measurements and independently simulated results.

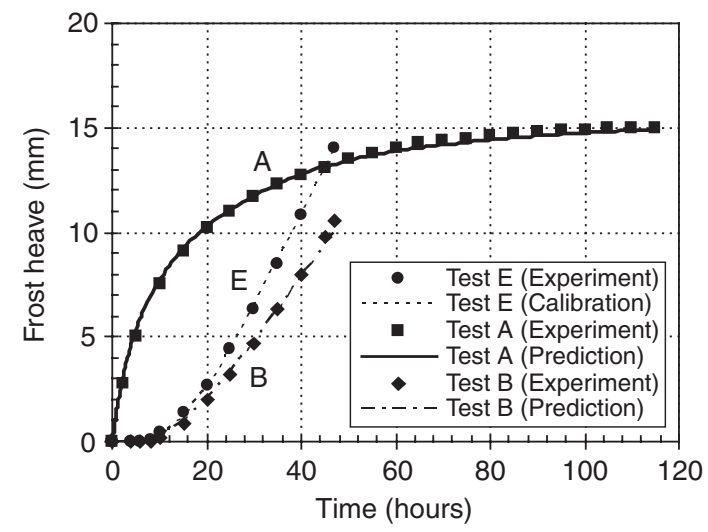

Figure 13. Ramped temperature frost heave process used in model calibration (E), and predictions for step freezing (A) and ramped temperature (B) processes.

that associated with in situ freezing, Figure 11(b). The growth of porosity is illustrated in Figure 11(c).

The measured frost heave and the propagation of the freezing front were compared to the independently simulated results, and this comparison is shown in Figure 12. The simulation falls remarkably close to the experimental measurements for both the frost heave prediction and the freezing front propagation. Hence, the model appears to predict the global (macroscopic) effect of heaving well. To emphasize the significant difference in the data used for calibration and prediction, the frost heave for these processes is demonstrated on one graph in Figure 13. E illustrates the calibration curve using a ramped temperature process with an average gradient of $0.43^{\circ} \mathrm{C} \mathrm{cm}^{-1}$, whereas A and B are both predictions: A for a step-freezing process, and $\mathrm{B}$ for a ramped temperatures with a gradient of $1.0^{\circ} \mathrm{C} \mathrm{cm}^{-1}$. 


\section{IMPLEMENTATION OF THE MODEL}

The model has been implemented in the finite element code ABAQUS, and a simulation of the freezing of a vertical cut in a frost susceptible soil is illustrated next. The geometry of the vertical cut and the thermal initial/boundary conditions are shown in Plates 1(a) and (b). The most left and right vertical boundaries are adiabatic. The initial temperature of the bottom boundary is $4^{\circ} \mathrm{C}$ and the temperature along the 'external' boundaries is $2^{\circ} \mathrm{C}$. The steady-state distribution of the temperature before the process started at $t=0$ is shown in Plate 1(c). At time $t=0$ the external temperature starts decreasing at a constant rate from $2{ }^{\circ} \mathrm{C}$ to $-2^{\circ} \mathrm{C}$ in 20 days. The material properties adopted for this simulation are those obtained from the model calibration.

As the freezing front starts propagating into the soil after 10 days, the soil starts heaving vertically along horizontal segments $\mathrm{AB}$ and $\mathrm{CD}$, but the heave is horizontal along $\mathrm{BC}$. This is because the bulk of the heaving occurs in the direction of heat flow, as prescribed by parameter $\xi=0.9$ in Equation (4). The cut, originally vertical, now has a tendency to tilt, since the horizontal displacement in its upper part is not restricted, whereas at the bottom it is confined by segment CD. Similarly, the vertical heave of segment CD is inhibited at point C. Consequently, after some freezing process has taken place, boundary segments $\mathrm{BC}$ and $\mathrm{DC}$ meet at corner $\mathrm{C}$ at an acute angle. The displacements illustrated in Plate 2 are exaggerated by a factor of 2 . The simulation appears to yield reasonable results, and it is likely that the model will be useful in predicting the consequences of freezing around pipelines, culverts, retaining structures, etc.

\section{FINAL REMARKS}

Efforts toward modelling of frost susceptible soils have not, so far, yielded a constitutive model that would be accepted widely by engineers. The model presented here belongs to the category of thermomechanic models, and makes it possible to use the continuum mechanics framework to implement it in solving boundary value problems. The model's utility is its prime benefit. Formation of individual ice lenses is not modelled; instead, ice growth is considered as a constitutive function reflected in the porosity growth. The porosity growth, however, is represented as a function that does replicate the physical process dependent on the temperature, temperature gradient, and the stress state. Calibration and validation of the model reveals that it is capable of reproducing true heave and heave rate; therefore, the model is expected to be useful as a practical tool when implemented in a finite element code. Future research will include validation of the model for a larger variety of soils, and its implementation in engineering boundary value problems where frost heaving is an important issue, e.g. pipelines, culverts, etc.

Freezing and frost heaving is part of the seasonal freeze-thaw cycle, and the model presented in this paper will constitute a component of a more comprehensive model of freezing and thawsoftening of frost-susceptible soils.

\section{NOMENCLATURE}

a parameter describing the rate of unfrozen water decay in frozen soil $c^{\mathrm{w}}, c^{\mathrm{i}}, c^{\mathrm{s}} \quad$ heat capacities of water, ice, and solid skeleton per unit mass $C \quad$ heat capacity per unit volume of the mixture 
$\mathrm{d} \varepsilon_{i j}, \mathrm{~d} \varepsilon_{i j}^{\mathrm{e}}, \mathrm{d} \varepsilon_{i j}^{\mathrm{p}} \quad$ total strain increment, elastic strain increment, and strain increment due to growth of porosity

$E, G \quad$ Young's and shear moduli

$g_{\mathrm{T}} \quad$ temperature gradient at which $\dot{n}_{\mathrm{m}}$ was determined

$l \quad$ heat flow direction

$L \quad$ latent heat of water fusion per unit mass

$n \quad$ soil porosity

$\dot{n}_{i j} \quad$ porosity growth tensor

$\dot{n}_{\mathrm{m}} \quad$ maximum rate or porosity

$t \quad$ time

$T \quad$ temperature

$T_{\mathrm{m}} \quad$ temperature at which maximum porosity rate occurs

$T_{0} \quad$ freezing point of water

$w \quad$ gravimetric water content (as fraction of dry weight)

$\bar{w} \quad$ lower bound of water content in the soil at freezing point

$w^{*} \quad$ unfrozen water content at a low reference temperature

Greek letters

$\begin{array}{ll}\alpha_{i j} & \text { unit growth tensor } \\ \zeta & \text { stress parameter in porosity rate function } \\ \theta & \text { angle that heat flow direction makes with } x \text {-axis } \\ \theta^{\mathrm{w}}, \theta^{\mathrm{i}}, \theta^{\mathrm{s}} & \text { volumetric fractions of water, ice, and solid skeleton } \\ \lambda & \text { thermal conductivity of the mixture } \\ \lambda^{\mathrm{w}}, \lambda^{\mathrm{i}}, \lambda^{\mathrm{s}} & \text { thermal conductivity of water, ice, and solid skeleton } \\ \mu & \text { Poisson's ratio } \\ v & \text { unfrozen water concentration in frozen soil } \\ \xi & \text { parameter describing anisotropic growth of ice } \\ \rho & \text { mass density of the mixture } \\ \rho^{\mathrm{w}}, \rho^{\mathrm{i}}, \rho^{\mathrm{s}} & \text { mass density of water, ice, and solid skeleton } \\ \sigma_{i j} & \text { Cauchy stress tensor (total stress) }\end{array}$

ACKNOWLEDGEMENT

The research presented in this paper was supported by the U.S. Army Research Office, Grant No. DAAD19-03-1-0063. This support is greatly appreciated.

\section{REFERENCES}

1. Taber S. Frost heaving. Journal of Geology 1929; 37:428-461.

2. Taber S. The mechanics of frost heaving. Journal of Geology 1930; 38(4):303-317.

3. Beskow G. Soil Freezing and Frost Heaving with Special Application to Roads and Railroads. Northwestern University, 1947 (Translated by Osberberg JO).

4. Everett DH. The thermodynamics of frost damage to porous solid. Transactions of the Faraday Society 1961; 57:1541-1551.

5. Penner E. The mechanism of frost heave in soils. Highway Research Board Bulletin 1959; 225:1-22. 


\section{R. L. MICHALOWSKI AND M. ZHU}

6. Miller RD. Frost heaving in non-colloidal soils. Third International Conference on Permafrost, Edmonton, 1978; $707-713$.

7. O'Neill K, Miller RD. Numerical solutions for a rigid ice model of secondary frost heave. 2nd International Symposium on Ground Freezing, Trondheim, 1980; 656-669.

8. O'Neill K, Miller RD. Exploration of a rigid ice model of frost heave. Water Resources Research 1985; 21:1-22.

9. Römkens MJM, Miller RD. Migration of mineral particles in ice with a temperature gradient. Journal of Colloid and Interface Science 1973; 42:103-111.

10. Sheng D, Axelsson K, Knuttson S. Frost heave due to ice lens formation in freezing soils. 1. Theory and verification. Nordic Hydrology 1995; 26:125-146.

11. Konrad JM, Morgenstern NR. The segregation potential of a frozen soil. Canadian Geotechnical Journal 1981; 18:482-491.

12. Kay BD, Sheppard MI, Loch JPG. A preliminary comparison of simulated and observed water redistribution in soils freezing under laboratory and field conditions. Proceedings of the International Symposium on Frost Action in Soils, vol. 1, Luleå, 1977; 42-53.

13. Taylor GS, Luthin JN. A model for coupled heat and moisture transfer during soil freezing. Canadian Geotechnical Journal 1978; 15:548-555.

14. Shen M, Ladanyi B. Modelling of coupled heat, moisture and stress field in freezing soil. Cold Regions Science and Technology 1987; 14:237-246.

15. Frémond M. Personal communication, 1987.

16. Michalowski RL. A constitutive model for frost susceptible soils. In Proceedings of the 4th International Symposium on Numerical Models in Geomechanics, Pande GN, Pietruszczak S (eds). Swansea, 1992; 159-167.

17. Michalowski RL. A constitutive model of saturated soils for frost heave simulations. Cold Regions Science and Technology 1993; 22(1):47-63.

18. Hartikainen J, Mikkola M. General thermomechanical model of freezing soil with numerical application. In Ground Freezing 97, Knutsson S (ed.). Balkema: Luleå, 1997; 101-105.

19. Penner E. Aspects of ice lens growth in soils. Cold Regions Science and Technology 1986; 13:91-100.

20. Williams PJ, Wood JA. Internal stresses in frozen ground. Canadian Geotechnical Journal 1985; 22:413-416.

21. McCabe EY, Kettle RJ. Thermal aspects of frost action. 4th International Symposium on Ground Freezing, Sapporo, 1985; 47-54.

22. Fukuda M, Kim H, Kim Y. Preliminary results of frost heave experiments using standard test sample provided by TC8. Proceedings of the International Symposium on Ground Freezing and Frost Action in Soils, Luleå, Sweden, 1997; $25-30$.

23. Anderson DM, Tice AR. The unfrozen interfacial phase in frozen water systems. In Ecological Studies: Analysis and Synthesis, vol. 4, Hadar A (ed.). Springer: New York, 1973; 107-124.

24. Blanchard D, Frémond M. Soil frost heaving and thaw settlement. 4th International Symposium on Ground Freezing, Sapporo, 1985; 209-216.

25. Ladanyi B, Shen M. Freezing pressure development on a buried chilled pipeline. Proceedings of the 2nd International Symposium on Frost in Geotechnical Engineering, Anchorage, AK, 1993; 23-33.

26. Williams PJ, Smith MW. The Frozen Earth, Fundamentals of Geocryology. Cambridge University Press: Cambridge, 1989.

27. Selvadurai APS, Hu J, Konuk I. Computational modeling of frost heave induced soil-pipeline interaction: I. Modeling of frost heave. Cold Regions Science and Technology 1999; 29:215-228. 

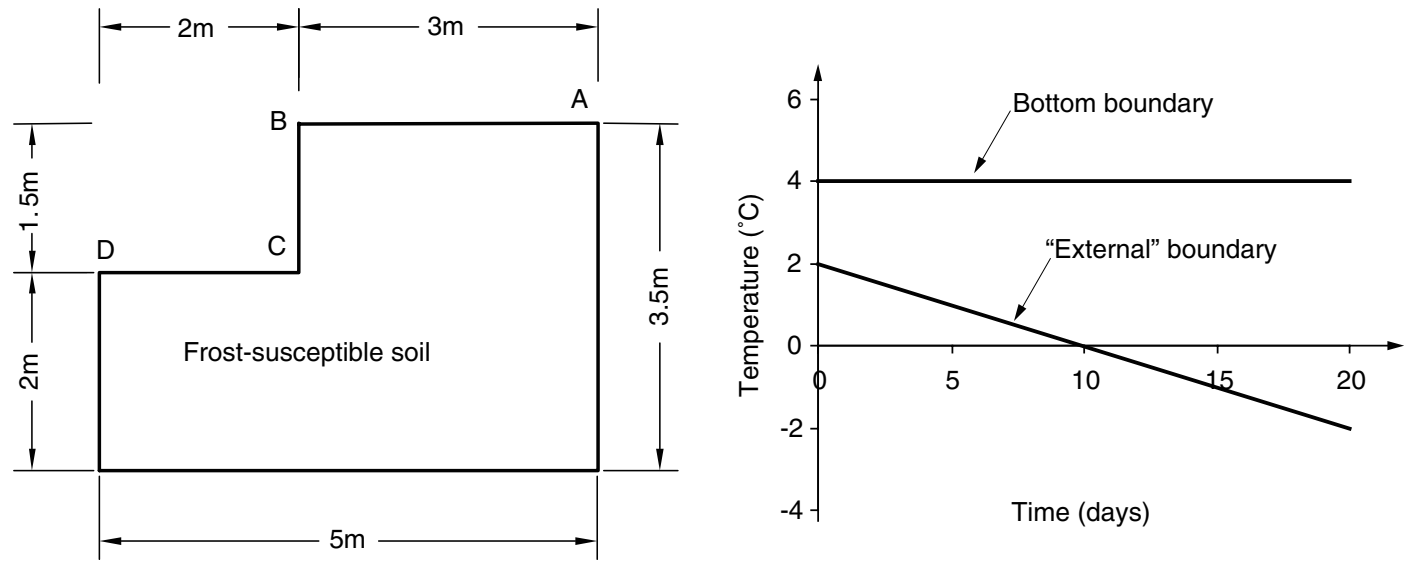

(a)

(b)
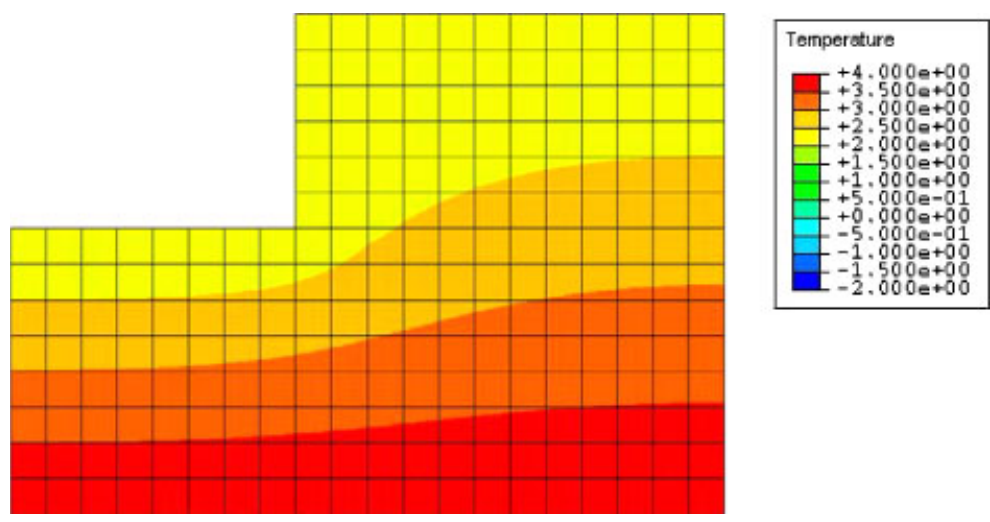

(c)

Plate 1. Vertical cut: (a) geometry; (b) initial/boundary conditions; and (c) steady-state temperature distribution at $t=0$. 

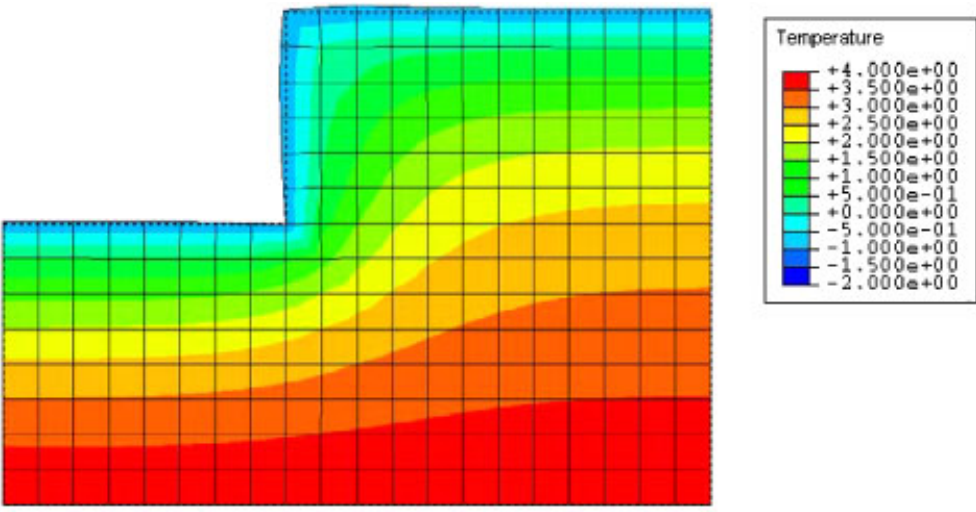

(a)
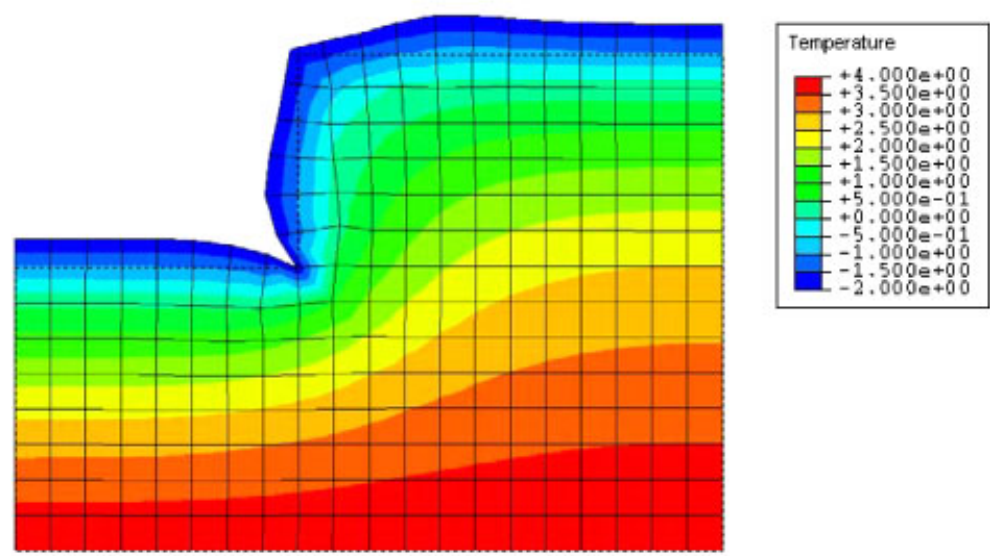

(b)

Plate 2. Vertical cut: displacements at $t=15$ days and $t=20$ days (exaggerated by a factor of 2). 